\title{
Comparison between intravenous and oral postoperative adjuvant immunochemotherapy in patients with stage III colorectal cancer
}

\author{
ISAO ITO $^{1}$, MASAYA MUKAI ${ }^{2}$, HIROMI NINOMIYA ${ }^{1}$, KYOKO KISHIMA $^{2}$, KAZUTOSHI TSUCHIYA ${ }^{3}$, \\ TAKAYUKI TAJIMA ${ }^{2}$, MASATO NAKAMURA $^{4}$ and HIROYASU MAKUUCHI ${ }^{5}$ \\ ${ }^{1}$ Tokai University Oiso Hospital, Department of Surgery, Gakyou 21-1, Oiso, Kanagawa 259-0198; \\ ${ }^{2}$ Tokai University Hachioji Hospital, Department of Surgery, Ishikawa-cho 1838, Hachioji, Tokyo 192-0032; \\ ${ }^{3}$ Tokai University Oiso Hospital, Department of Endoscopy, Gakyou 21-1, Oiso, Kanagawa 259-0198; Departments of \\ ${ }^{4}$ Pathology and ${ }^{5}$ Surgery, Tokai University School of Medicine, Bohseidai, Isehara, Kanagawa 259-1193, Japan
}

Received August 11, 2008; Accepted September 26, 2008

DOI: $10.3892 /$ or_00000174

\begin{abstract}
This study aimed to retrospectively assess the efficacy of postoperative adjuvant chemotherapy in 77 patients who underwent curative resection for stage III colorectal cancer. They were treated by intravenous administration of 5 FU + LV (FL-IV group, 38) or oral administration of UFT + PSK (oral group, 39). The 3-year relapse-free (3Y-RFS), 5-year relapse-free (5Y-RFS) and 5-year overall survival (5Y-OS) were calculated for each group, and clinical results and adverse events (AEs) were compared between the two groups. The 3Y-RFS, 5Y-RFS and 5Y-OS were 65.8, 62.7 and 72.3\%, respectively, in the FL-IV group and 63.3 ( $\mathrm{p}=0.7957), 56.3$ $(\mathrm{p}=0.7088)$ and $60.4 \%(\mathrm{p}=0.5293)$, respectively, in the oral group. These parameters showed no significant differences between the two groups. As AEs, grade 3 leucopenia, nausea/ vomiting, and general fatigue were noted in one patient each $(2.6 \%)$ in the FL-IV group. Grade 3 or more severe AEs were not noted in the oral group. These results suggest that oral immunochemotherapy is one of the options of postoperative adjuvant therapy for stage III colorectal cancer, because it imposes no financial burden on patients and results in high quality of life.
\end{abstract}

Correspondence to: Dr Isao Ito, Tokai University Oiso Hospital, Department of Surgery, Gakyou 21-1, Oiso, Kanagawa 259-0198, Japan

E-mail: isaoito@is.icc.u-tokai.ac.jp

Abbreviations: ONCs, occult neoplastic cells; AEs, adverse events; 5-FU, 5-fluorouracil; LV, leucovorin; UFT, tegafur/uracil; 3Y-RFS, 3-year relapse-free survival; 5Y-RFS, 5-year relapse-free survival; 5Y-OS, 5-year overall survival; CPT-11, irinotecan; LOHP, oxaliplatin; ITCs, isolated tumor cells

Key words: colorectal cancer, adjuvant chemotherapy, oral immunochemotherapy, 5-fluorouracil/leucovorin, tegafur/uracil, PSK (Krestin), occult neoplastic cells

\section{Introduction}

In Japan, clinical results of primary colorectal cancer have shown marked improvement with advances not only in surgical techniques but also in adjuvant therapy, including chemotherapy and radiotherapy. It has been reported that the 5-year survival was $\sim 60-70 \%$ (colon, $74.0 \pm 3.5 \%$ and rectum, $64.7 \pm 4.3 \%$ ) even in stage III/Dukes' C patients with lymph node metastasis (1-3). However, it has also been reported that despite radical curative resection, distant metastasis/recurrence occurred in $\sim 30-40 \%$ of Dukes' C patients, resulting in a decrease of survival (2-4). Lethal distant hematogenous metastasis/recurrence in the liver, lungs and other organs after curative resection appears to occur when residues of cancer cells that circulate in the body during the perioperative period escape from the immune defense system and proliferate in the hepatic or pulmonary microenvironments, which favor individual cancer cells $(5,6)$. It has been reported that such cancer cells, especially immunohistochemically cytokeratinpositive occult neoplastic cells (ONCs) in lymph node sinuses distant from primary lesions, are closely related to cancer metastasis and recurrence (7-11). ONCs in lymph node microcirculation, in the immune defense system of the body, were detected by semiquantitatively counting extremely small numbers of malignant cells by immunostaining, a relatively easy method $(5,6)$. Development of these ONCs is noted in at least $80 \%$ of stage II/III patients with recurrence. Since ONC-clusters $(\leq 10$ ONCs) $\sim 0.2 \mathrm{~mm}$ in diameter which contain many ONCs and malignant micro-aggregates $(>10$ ONCs) are present in stage III patients with lymph node metastasis, it has been reported that this type of metastasis should be clearly differentiated from isolated tumor cells (ITCs $\leq 0.2 \mathrm{~mm})$ and micrometastasis $(0.2 \mathrm{~mm}<\mathrm{MM} \leq 2 \mathrm{~mm})$ in lymph nodes and classified as more malignant occult systemic metastasis due to occult transplant foci (12-14). Thus, the most important factor in postoperative adjuvant chemotherapy is to eradicate these circulating clusters and aggregate-type free cancer cells that develop during the perioperative period (14-16). 
According to the NSABP-C06 study on stage III colorectal cancer patients with lymph node metastasis, the efficacy of standard intravenous 5-FU/LV therapy (RPMI regimen) was equal to that of oral 5-FU/LV therapy (UFT/UZEL; Taiho Pharmaceutical Co., Ltd., Tokyo, Japan) $(17,18)$. Attention has been focused on the efficacy of oral fluoropyrimidine drugs in Western countries (17-19). In Japan, since the latter half of 1990, oral fluoropyrimidine drugs have been administered at outpatient clinics mostly to stage III/Dukes' C colorectal cancer patients, after completion of intravenous administration, and stage II/Dukes' B patients postoperatively (20-22). Oral immunochemotherapy (UFT/PSK) in which an oral immunoactivator (PSK; Kureha Chemical Industry Co., Ltd., Tokyo, Japan) is combined as a biological response modifier/immune modulator has come into wide clinical use (20-22). Since oral PSK was developed to enhance non-specific immunity, and not as a chemical modulator or stimulator for 5FU derivatives, it has not been approved in Western countries, although medical evidence of its high efficacy has been reported by many researchers (23-29).

However, in Japan no reports have been published comparing the efficacy between the intravenous administration of high-dose 5-FU/LV (FL-IV group) and oral administration of UFT + PSK (oral group) in stage III/Dukes' C patients after curative resection of colorectal cancer. Therefore, this study was conducted to compare clinical results and adverse events (AEs) of postoperative adjuvant therapy between FL-IV and oral groups of stage III cancer patients.

\section{Patients and methods}

Of 164 stage III primary colorectal cancer patients who underwent radical curative resection during the 10 years from 1995 to 2005, patients who met the following criteria were subjects of this study: i) those aged 75 years or younger with performance status of 0 or 1 and ii) those who could be followed for recurrence and survival because their complete medical records were reliably retained. As a result, 77 pathological lymph node positive/stage III patients (FL-IV group, $\mathrm{n}=38$ and oral group, $\mathrm{n}=39$ ) were enrolled in this study. In the FL-IV group, modified Machover's regimen in which highdose $5-\mathrm{FU}+\mathrm{LV}$ were administered for 5 consecutive days once a month $\left(5-\mathrm{FU} 350+\mathrm{LV} 150 \mathrm{mg} / \mathrm{m}^{2} \times 5\right.$ consecutive days/month $\times 3-6$ months) was followed by oral therapy with UFT $400 \mathrm{mg} / \mathrm{m}^{2}+$ PSK $3.0 \mathrm{~g} /$ body x 5 consecutive days per week/weekends off for 3 months or longer $(30,31)$ (Fig. 1). In the oral group, intravenous administration was not performed, and only oral immunochemotherapy with UFT $400 \mathrm{mg} / \mathrm{m}^{2}+$ PSK $3.0 \mathrm{~g} /$ body $\mathrm{x} 5$ consecutive days per week/ weekends off for 3 months or longer was performed $(21,22,31)$ (Fig. 1).

Eligibility and adverse events. The eligibility of stage III patients for each regimen was evaluated. Intravenous injection by physicians or nurses was confirmed by reviewing clinical records, and the total and mean numbers of courses were calculated for patients who did not receive $<3$ courses and not $>6$ courses postoperatively. Compliance with oral drug therapy was confirmed from prescriptions completed by physicians and nurses in the clinical records and results of a questionnaire on drug administration. The total and mean periods of treatment were calculated for patients in whom at least 3 months of treatment without interruptions of one month or longer could be confirmed. The presence of distant metastasis/recurrence was confirmed at 3-month intervals from after 3 months postoperatively, and from the time when a radiologist detected a metastatic lesion by US and CT examinations was regarded as the onset of clinical recurrence. Under these conditions, the 3-year relapse-free (3Y-RFS), 5year relapse-free (5Y-RFS) and 5-year overall survival (5Y-OS) rates were calculated for each group of stage III patients and retrospectively compared between the two groups. In the FL-IV and oral groups, the severity of hematological and non-hematological adverse events was graded according to the JCOG/JSCO (Japan Clinical Oncology Group/Japanese Society of Clinical Oncology) CTCAE, version 3.0 after 1-3 courses of treatment. The grade of each event was compared between the two groups.

Statistical analysis. The 3-year relapse-free, 5-year relapsefree and 5 -year overall survival rates were calculated by the Kaplan-Meier method, and the log-rank test was used to compare the two groups. $\mathrm{P}<0.05$ was considered to indicate a significant difference in all analyses, which were performed with SPSS 13.0 J software (SPSS Japan, Inc., Tokyo, Japan).

\section{Results}

In 38 patients in the FL-IV group, the number of courses was $\geq 3$ in 4 patients and $\geq 5$ in 34 patients. The total number of courses was 207 and the mean number was 5.4. The period of subsequent oral chemotherapy was $<1$ year in 13 patients and $\geq 1$ year in 25 patients. The total period of treatment was 82.9 years and the mean period of treatment was 2.2 years. In the 39 patients from the oral group, the period of treatment was $<1$ year in 13 patients and $\geq 1$ year in 26 patients. The total period of treatment was 74.9 years and the mean period of treatment was 1.9 years. The 3Y-RFS, 5Y-RFS and 5Y-OS were $65.8,62.7$ and $72.3 \%$, respectively, in the FL-IV group and $63.3 \%$ ( $\mathrm{p}=0.7957$; not significant, N.S.) (Fig. 2), 56.3\% ( $\mathrm{p}=0.7088$, N.S.) (Fig. 3) and $60.4 \%$ (p=0.5293, N.S.) (Fig. 4), respectively, in the oral group.

In the FL-IV group, in addition to various grade 1-2 adverse events, leucopenia (2.6\%, 1/38 patients) as a hematological toxicity, and nausea/vomiting $(2.6 \%, 1 / 38$ patients $)$ and general fatigue $(2.6 \%, 1 / 38$ patients $)$ as non-hematological toxicities were observed as grade 3 adverse events, but there were no grade 4 adverse events (Table I). In the oral group, leucopenia (10.3\%, 4/39 patients) as a hematological toxicity and nausea/vomiting (17.9\%, 7/39 patients), appetite loss (7.7\%, 3/39 patients), diarrhea (7.7\%, 3/39 patients) and general fatigue $(7.7 \%, 3 / 39$ patients) as non-hematological toxicities were noted as grade 1 or 2 adverse events, but there were no grade 3 or 4 adverse events (Table II).

\section{Discussion}

For effective postoperative adjuvant chemotherapy to control distant metastasis/recurrence after curative resection of primary lesions, it is very important to eradicate residual 
A) FL-IV group: 5-FU/LV

5 consecutive days (1-5) per week / month / 1 course

$5 \sqrt{5} \sqrt{2}$

$\nabla \nabla \nabla \nabla$

$30 / 3$ courses -6 courses, and UFT + PSK / 3 months or more*

(1) 5-FU; $350 \mathrm{mg} / \mathrm{m}^{2}$ (5 consecutive infusions / month)

- LV; $150 \mathrm{mg} / \mathrm{m}^{2}(5$ consecutive infusions / month)

* UFT; $400 \mathrm{mg} / \mathrm{m}^{2}+\mathrm{PSK} ; 3.0 \mathrm{~g} / \mathrm{body}$

\section{B) Oral group: UFT/PSK}

5 consecutive days (1-5) on/weekends off per week / month / 1 course x 3 months or more* * UFT; $400 \mathrm{mg} / \mathrm{m}^{2}+$ PSK; $3.0 \mathrm{~g} / \mathrm{body}$

Figure 1. Schedules for postoperative adjuvant chemotherapy with the modified Machover's regimen (5-FU/LV intravenous group: $350 \mathrm{mg} / \mathrm{m}^{2}$ of 5 -FU + $150 \mathrm{mg} / \mathrm{m}^{2}$ of LV on 5 consecutive days/month) and chemotherapy was continued for at least 3-6 courses postoperatively followed by oral UFT/PSK (A) FLIV group. Schedule for oral UFT/PSK alone group was administered for 5 consecutive days (1-5) on/weekends off per week/month/1 course for at least 3 months or more (UFT; $400 \mathrm{mg} / \mathrm{m}^{2}+$ PSK; $3.0 \mathrm{~g} /$ body) without 5-FU/LV injection (B) oral group.

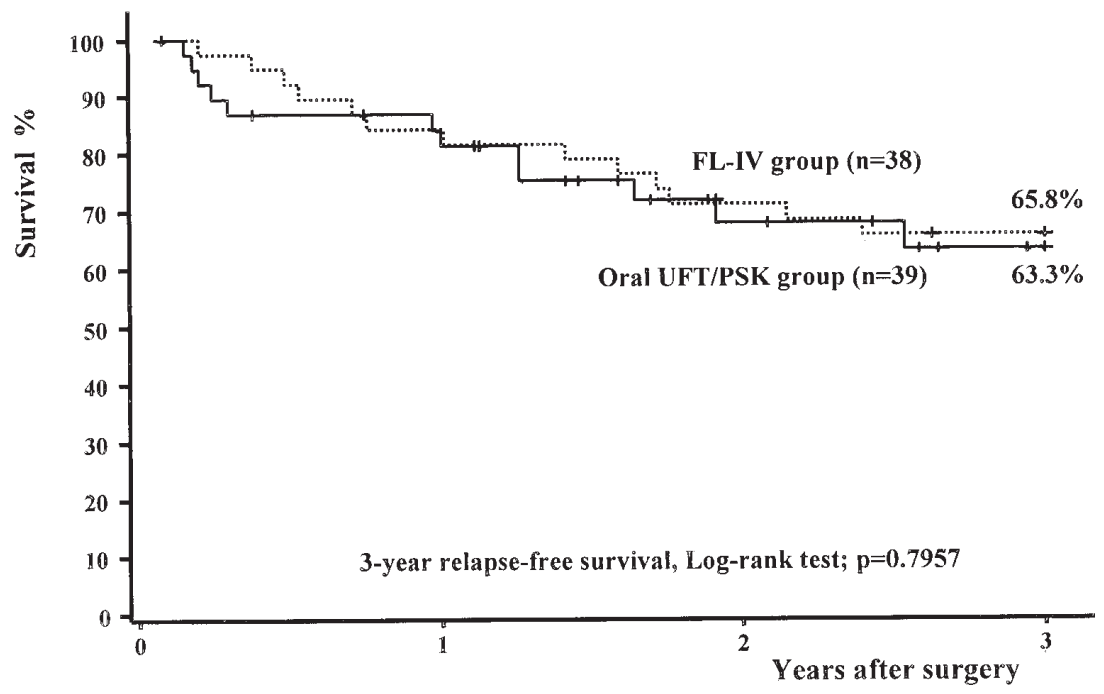

Figure 2. Three-year relapse-free survival rate of 77 patients with stage III colorectal cancer when comparing the 5-FU/LV intravenous (FL-IV) and oral UFT/PSK groups. The rate was $65.8 \%$ for 38 patients in the FL-IV group vs. $63.3 \%$ for 39 patients in the oral group (p=0.7957).

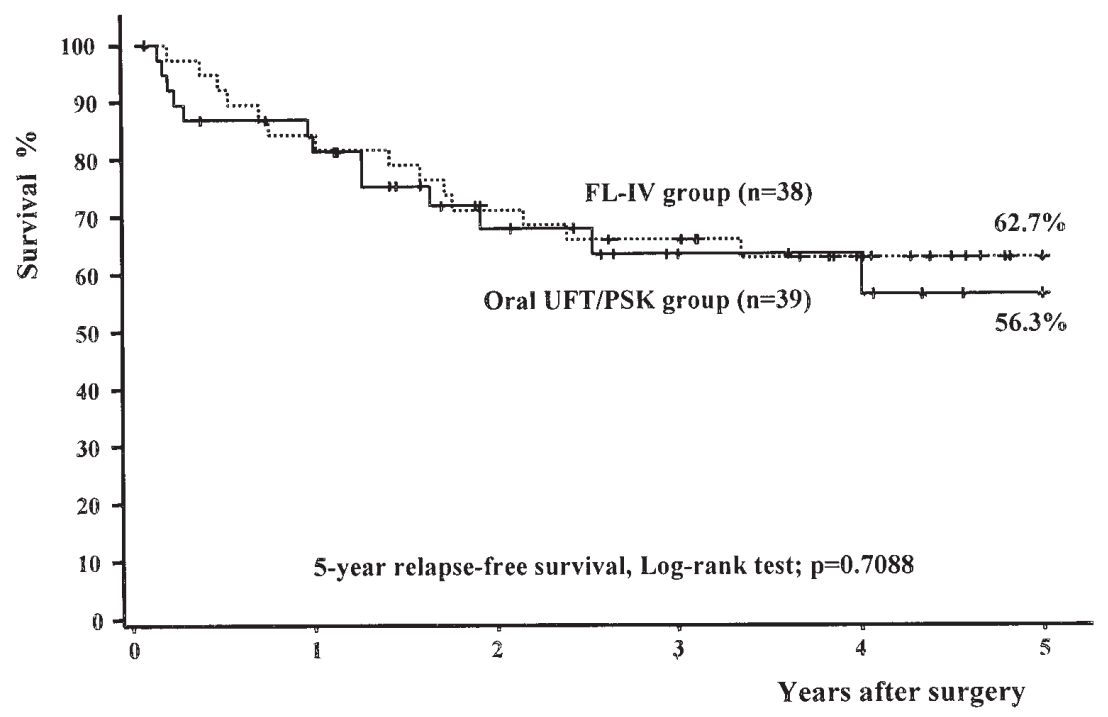

Figure 3. Five-year relapse-free survival rate of 77 patients with stage III colorectal cancer when comparing the 5-FU/LV intravenous (FL-IV) and oral UFT/PSK groups. The rate was $62.7 \%$ for 38 patients in the FL-IV group vs. $56.3 \%$ for 39 patients in the oral group ( $\mathrm{p}=0.7088$ ). 


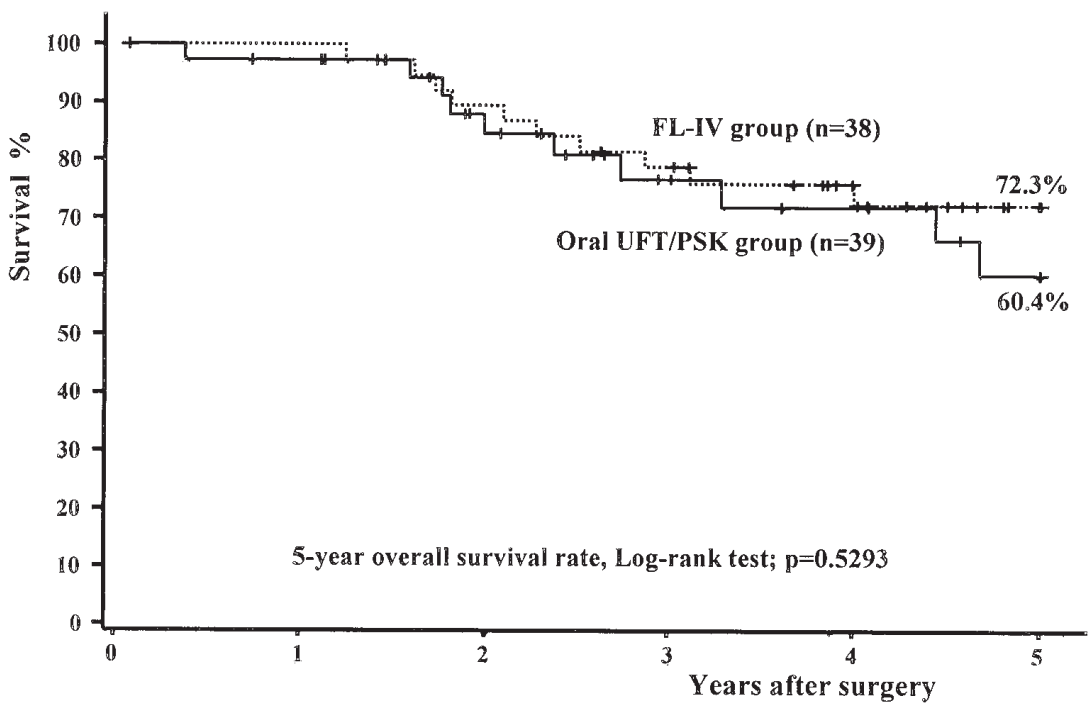

Figure 4. Five-year overall survival rate of 77 patients with stage III colorectal cancer when comparing the 5-FU/LV intravenous (FL-IV) and oral UFT/PSK groups. The rate was $72.3 \%$ for 38 patients in the FL-IV group vs. $60.4 \%$ for 39 patients in the oral group ( $\mathrm{p}=0.5293)$.

Table I. The adverse events were grade 3 leucopenia in 1/38 patients $(2.6 \%)$, nausea/vomiting in $1 / 38$ patients $(2.6 \%)$ and general fatigue in $1 / 38$ patients $(2.6 \%)$, respectively. ${ }^{a}$

\begin{tabular}{lrrrll}
\hline Grade (n=38) & 1 & 2 & 3 & 4 & Grade $\geq 3$ \\
\hline Leucopenia & 6 & 1 & 1 & 0 & $1(2.6 \%)$ \\
Anemia & 9 & 0 & 0 & 0 & 0 \\
Thrombocytopenia & 2 & 0 & 0 & 0 & 0 \\
T.bil elevation & 6 & 0 & 0 & 0 & 0 \\
AST elevation & 0 & 1 & 0 & 0 & 0 \\
ALT elevation & 0 & 1 & 0 & 0 & 0 \\
Nausea/vomiting & 10 & 1 & 1 & 0 & $1(2.6 \%)$ \\
Appetite loss & 4 & 2 & 0 & 0 & 0 \\
Diarrhea & 4 & 2 & 0 & 0 & 0 \\
General fatigue & 6 & 0 & 1 & 0 & $1(2.6 \%)$ \\
Pigmentation & 3 & 0 & 0 & 0 & 0 \\
Mucositis & 4 & 2 & 0 & 0 & 0 \\
Alopechia & 2 & 0 & 0 & 0 & 0 \\
Taste abnormality & 0 & 0 & 0 & 0 & 0
\end{tabular}

${ }^{a}$ In the FL-IV group, grade 1 or 2 adverse events were noted, but there were no grade 4 adverse events.

cancer cells, especially ONC-clusters, which may separate from primary lesions and circulate systemically in a viable state during the perioperative period (14-16). It is very effective to perform more sensitive systemic consolidated chemotherapy early postoperatively. In stage II patients without lymph node metastasis, the $5 \mathrm{Y}-\mathrm{OS}$ was as high as $80-85 \%$, and recurrence occurred in $\sim 15-20 \%$, a relatively low rate. It has been reported that the non-specific immunoactivating effect of PSK was more marked in stage II/NO-localized disease patients, with
Table II. The only adverse events were grade 1 or 2 hematological or non-hematological toxicities, while no grade 3 or 4 adverse events were detected in the oral group.

\begin{tabular}{lccccc}
\hline Grade (n=39) & 1 & 2 & 3 & 4 & Grade $\geq 3$ \\
\hline Leucopenia & 3 & 1 & 0 & 0 & 0 \\
Anemia & 8 & 1 & 0 & 0 & 0 \\
Thrombocytopenia & 2 & 0 & 0 & 0 & 0 \\
T.bil elevation & 2 & 1 & 0 & 0 & 0 \\
AST elevation & 4 & 0 & 0 & 0 & 0 \\
ALT elevation & 4 & 0 & 0 & 0 & 0 \\
Nausea/vomiting & 5 & 2 & 0 & 0 & 0 \\
Appetite loss & 3 & 0 & 0 & 0 & 0 \\
Diarrhea & 2 & 1 & 0 & 0 & 0 \\
General fatigue & 2 & 1 & 0 & 0 & 0 \\
Pigmentation & 0 & 0 & 0 & 0 & 0 \\
Mucositis & 0 & 0 & 0 & 0 & 0 \\
Alopechia & 1 & 1 & 0 & 0 & 0 \\
Taste abnormality & 0 & 0 & 0 & 0 & 0 \\
\hline
\end{tabular}

small numbers of single ONCs presumably in the intraportal circulation, than in stage III patients $(20,21)$. Furthermore, because there was no difference in efficacy between the FL-IV and oral groups in stage II patients, oral UFT + PSK therapy was considered to be adequate for eliminating circulating single ONCs. In this therapy, the immune-inductive effect of PSK was presumably added to the effect of the oral anticancer drug $(20,31)$. However, since recurrence control by these drugs is estimated to be $\sim 5-10 \%$ in stage II/recurrent patients, eradication of circulating ONC clusters and aggregates, which are considered to play the most important role in accidental distant metastasis/recurrence in stage II/III 
patients, remains a problem. It is assumed that in stage III patients with lymph node metastasis, ONC-clusters and aggregates develop at high frequencies and single ONCs in the portal vein look for target organs for metastasis, such as the liver and lungs, resulting in marked changes in the morphology and volume of scattered tumor cells (14-16). It has also been reported that the non-specific immunoactivating effect of PSK was weaker in stage III than in stage II patients, and therefore more potent multiple combination chemotherapy is thought to be effective in patients with systemic disease or occult systemic metastasis (20-22). The most important factor in such multi-drug combination therapy is the anticancer activity of the drugs used, although optimal administration and dosage are also important factors. In the recurrence group with $\mathrm{ONCs}$, the percentage of 5-FU/LV therapy-sensitive patients characterized by high-TS/low-DPD levels was low in stage II/III, and the possibility of inadequate drug potency was suggested $(32,33)$. Therefore, to improve drug potency and eradicate ONC-clusters, multiple consolidated chemotherapy with CPT-11 and L-OHP, such as FOLFILI, FOLFOX and IFL, which is more common in Western countries than in Japan, may be more effective (34-36). It has been reported that sensitivity of CPT-11 to ONC-clusters is almost equal to that of L-OHP $(37,38)$. For this reason, CPT-11, which causes fewer neurological adverse reactions, including paresthesia, and is cheaper, is a more reasonable first-line treatment after curative resection, while L-OHP should be reserved as second-line treatment in case of distant metastasis/recurrence, although the high price remains a problem in Japan.

According to the NSABP-C06 study, there was no difference in 5Y-RFS or 5Y-OS between oral 5-FU/ LV and intravenous 5-FU/LV as postoperative adjuvant chemotherapy in stage II/III patients $(17,18)$. However, in analyses using $5 \mathrm{Y}-\mathrm{RFS}$ or $5 \mathrm{Y}-\mathrm{OS}$, it is difficult to standardize criteria for resection/non-resection at the time of distant metastasis/ recurrence in the liver and lungs. Moreover, treatment after recurrence, including after second-line treatment with hepatic arterial infusion and XRT, is not standardized. Therefore, $3 \mathrm{Y}$ RFS is considered to reflect more accurately the inhibitory effect of the first-line drug administered soon after the operation for $\sim 6$ months. In this study, these values were exactly the same in the two groups $(\mathrm{p}=0.7957)$. It has been reported that oral 5-FU/ LV therapy improved patient quality of life more markedly than intravenous injection therapy, but the incidence of mild to moderate gastrointestinal symptoms, such as abdominal discomfort, nausea and anorexia, was relatively higher for oral therapy (17-19). Oral LV which is still more expensive than anticancer drugs is a financial burden on patients, while PSK is cheaper than anticancer drugs and causes few adverse reactions (20-22). In this study, the mean period of treatment with UFT/PSK was also long, $\sim 2$ years in each group, and this was presumably due to a very low incidence of adverse reactions and a very small number of patients who discontinued oral administration. The Japanese guidelines recommend intravenous administration of 5-FU/LV as first-line adjuvant therapy for stage III patients $(2,3)$. However, the results of this study suggest that oral UFT/PSK alone, which improves patient quality of life, is one of the options available for patients who wish to avoid intravenous administration, are dropouts due to adverse events and cannot afford the treatment. At present, a prospective study of stage II/III postoperative patients is already in progress, in which one standardized treatment is specified for each stage (III: 5FU/LV-IV and II: oral UFT/PSK) and patients are classified into subgroups in terms of high or low risk of metastasis/recurrence and presence of ONCs. We anticipate the results of the final analysis, including $5 \mathrm{Y}-\mathrm{OS}$ data, at the end of 2009 (15).

It has been reported that the most important survival benefit for patients is improvement of survival after recurrence $(39,40)$. In stage III colorectal cancer patients at a high risk of recurrence when ONC-clusters begin to develop, it is necessary to select appropriate treatment for early eradication of residual cancer cells after curative resection in the stage of occult metastatic or occult transplant foci in the liver, lungs and other sites during the perioperative period, which appears to be the period of occult systemic metastasis before recurrence. It is also important to perform more potent consolidated chemotherapy in which multiple drugs with higher sensitivity are combined to avoid the problem of inadequate drug potency.

\section{Acknowledgements}

This study was supported by grants from the Occult Neoplastic Cells Research and Study Group (no. 2008-5007; Tokai University Hachioji Hospital, Tokyo, Japan) and the Research and Study Program of Tokai University Educational System General Research Organization (no. 2007-04; Tokai University School of Medicine, Kanagawa, Japan).

\section{References}

1. Multi-Institutional Registry of Large Bowel Cancer in Japan, Vol. 23, cases treated in 1994. Japanese Society for Cancer of the Colon and Rectum, Tokyo, 2002.

2. Knacks and Pitfalls: Surgery of the Colon, Rectum and Anus (2nd edition). Sugihara K (ed.), Bunkoudou Co., Ltd., Tokyo, 2004.

3. Guideline for Large Bowel Cancer in Japan. Japanese Society for Cancer of the Colon and Rectum, Tokyo, 2005.

4. Mukai M, Ito I, Mukoyama S, Tajima T, Saito Y, Nakasaki H, Sato $\mathrm{S}$ and Makuuchi $\mathrm{H}$ : Improvement of 10 -year survival by Japanese radical lymph node dissection in patients with Dukes' $\mathrm{B}$ and C colorectal cancer: A 17-year retrospective study. Oncol Rep 10: 927-934, 2003.

5. Mukai M, Sato S, Komatsu N, Nishida T, Shiba K, Ito I, Nakasaki $\mathrm{H}$ and Makuuchi H: Correlation between occult neoplastic cells in the lymph node sinuses and recurrence in patients with Dukes' C colorectal cancer. Oncol Rep 10: 1165-1169, 2003.

6. Mukai M, Sato S, Komatsu N, Nishida T, Shiba K, Ito I, Nakasaki H and Makuuchi H: Correlation between occult neoplastic cells in the lymph node sinuses and recurrence in patients with curatively resected Dukes' B colorectal cancer. Oncol Rep 10: 1177-1181,2003.

7. Mukai M, Sato S, Nakasaki H, Saito Y, Nishiumi N, Iwasaki M, Tokuda Y, Ogoshi K, Inoue H and Makuuchi H: Occult neoplastic cells in the lymph node sinuses and recurrence of primary breast, lung, esophageal and gastric cancer. Oncol Rep 11: 81-84, 2004

8. Mukai M, Sato S, Komatsu N, Kimura T, Ninomiya H, Nakasaki H, Ogoshi K and Makuuchi M: Accuracy of criteria for predicting the recurrence and metastasis of stage I and II gastric cancer without lymph node metastasis. Oncol Rep 12: $59-62,2004$

9. Mukai M, Sato S, Komatsu N, Kimura T, Ninomiya H, Nakasaki H, Ogoshi K and Makuuchi H: Accuracy of criteria for predicting recurrence and metastasis in stage II and III gastric cancer with lymph node metastasis. Oncol Rep 12: 63-66, 2004. 
10. Mukai M, Sato S, Komatsu N, Kimura T, Ninomiya H, Nakasaki H, Ogoshi K and Makuuchi H: Predicting the recurrence/metastasis of stage II and III breast cancer with lymph node metastasis. Oncol Rep 12: 303-306, 2004.

11. Mukai M, Sato S, Komatsu N, Kimura T, Ninomiya H, Nakasaki H, Ogoshi K and Makuuchi H: Predicting the recurrence/metastasis of stage I and II breast cancer without lymph node metastasis. Oncol Rep 12: 745-748, 2004.

12. Mukai M, Sato S, Nishida T, Komatsu N, Shiba K, Nakasaki H and Makuuchi H: Selection criteria for high risk and low risk groups of recurrence and metastasis in patients with primary colorectal cancer. Oncol Rep 10: 1753-1758, 2003.

13. TNM classification of malignant tumours (6th edition). John Wiley \& Sons, Inc., New York, 2002.

14. Mukai M: Occult neoplastic cells and malignant microaggregates in lymph node sinuses: Review and hypothesis. Oncol Rep 14: 173-175, 2005.

15. Mukai M, Sato S, Ninomiya H, Wakui K, Komatsu N, Tsuchiya K, Tajima T, Nakasaki H and Makuuchi H: Prospective study on the recurrence/metastasis of stage II/III colorectal and gastric cancer associated with occult neoplastic cells in lymph node sinuses: Three-year interim results. Oncol Rep 16: 405-410, 2006.

16. Mukai M, Oida Y, Tajima T, Kishima K, Ninomiya H, Sato S, Nakamura M, Nakasaki H and Makuuchi H: Alternating hepatic arterial infusion and systemic chemotherapy for stage IV colorectal cancer with synchronous liver metastasis. Oncol Rep 16: 865-870, 2006.

17. Wolmark N, Wieand S, Lembersky B, Colangelo L, Smith R and Pazdur R: A phase III trial comparing oral UFT to FULV in stage II and III carcinoma of the colon: results of NSABP protocol C-06. J Clin Oncol 22: 3508, 2004.

18. Lembersky BC, Wieand HS, Petrelli NJ, O'Connell MJ, Colangelo LH, Smith RE, Seay TE, Giguere JK, Marshall ME, Jacobs AD, Colman LK, Soran A, Yothers G and Wolmark N: Oral uracil and tegafur plus leucovorin compared with intravenous fluorouracil and leucovorin in stage II and III carcinoma of the colon: results from National Surgical Adjuvant Breast and Bowel Project Protocol C-06. J Clin Oncol 24: 2059-2064, 2006.

19. Mukai M, Moriya H, Himeno S, Oida Y, Mukoyama S, Nishi T, Nakasaki H, Sato S and Makuuchi H: Efficacy of oral UFT plus leucovorin therapy for colon cancer with ovarian and multiple liver metastases: Report of two cases. Oncol Rep 8: 1079-1083, 2001.

20. Mukai M, Tajima T, Nakasaki H, Sato S, Ogoshi K and Makuuchi H: Efficacy of postoperative adjuvant oral immunochemotherapy in patients with Dukes' B colorectal cancer. Ann Cancer Res Ther 11: 201-214, 2003.

21. Mukai M, Tajima T, Nakasaki H, Sato S, Ogoshi K and Makuuchi H: Efficacy of postoperative adjuvant oral immunochemotherapy in patients with Dukes' C colorectal cancer. Ann Cancer Res Ther 11: 215-229, 2003.

22. Mukai M, Tokunaga N, Yasuda S, Mukoyama S, Itoh I, Kameya T, Ishikawa K, Iwase H, Suzuki T, Ishida H, Sadahiro S and Makukuchi H: Long-term survival after immunochemotherapy in a patient of juvenile colon cancer with peritoneal dissemination: A case report. Oncol Rep 7: 1343-1347, 2000.

23. Mitomi T, Tsuchiya S, Iijima N, Aso K, Suzuki K, Nishiyama K, Amano T, Takahashi T, Murayama N, Oka H, Oya K, Noto T and Ogawa N: Randomized controlled study on adjuvant immunochemotherapy with PSK in curatively resected colorectal cancer. The Cooperative Study Group of Surgical Adjuvant Immunochemotherapy for Cancer of the Colon and Rectum (Kanagawa). Dis Colon Rectum 35: 123-130, 1992.

24. Nakazato H, Koike A, Saji S, Ogawa N and Sakamoto J: Efficacy of immunochemotherapy as adjuvant treatment after curative resection of gastric cancer. Lancet 33: 1122-1126, 1994.

25. Sakamoto J, Hamada C, Kodaira S, Nakazato H and Ohashi Y: Adjuvant therapy with oral fluoropyrimidines as main chemotherapeutic agents after curative resection for colorectal cancer: individual patient data meta-analysis of randomized trials. Jpn J Clin Oncol 29: 78-86, 1999.

26. Munemoto Y, Iida Y, Abe J, Saito H, Fujisawa K, Kasahara Y, Mitsui T, Asada Y and Miura S: Significance of postoperative adjuvant immunochemotherapy after curative resection of colorectal cancers: Association between host or tumor factors and survival. Int J Oncol 20: 403-411, 2002.
27. Koda K, Miyazaki M, Sarashina H, Suwa T, Saito N, Suzuki M, Ogawa K, Watanabe S, Kodaira S, and Nakazato H: A randomized controlled trial of postoperative adjuvant immunochemotherapy for colorectal cancer with oral medicines. Int J Oncol 23: 165-172, 2003.

28. Ohwada S, Ikeya T, Yokomori T, Kusaba T, Roppongi T, Takahashi T, Nakamura S, Kakinuma S, Iwazaki S, Ishikawa H, Kawate S, Nakajima T and Morishita Y: Adjuvant immunochemotherapy with oral Tegafur/Uracil plus PSK in patients with stage II or III colorectal cancer. Br J Cancer 90: 1003-1010, 2004.

29. Sakamoto J, Morita J, Oba K, Matsui T, Kobayashi M, Nakazato H and Ohashi Y: Efficacy of adjuvant immunochemotherapy with polysaccharide $\mathrm{K}$ for patients with curatively resected colorectal cancer: A meta-analysis of centrally randomized controlled clinical trials. Cancer Immunol Immunother 55: 404-411, 2006.

30. Machover D, Schwarzenberg L, Goldschmidt E, Tourani JM, Michalski B, Hayat M, Dorval T, Misset JL, Jasmin C, Maral R and Mathe G: Treatment of advanced colorectal and gastric adenocarcinomas with 5-FU combined with high-dose folinic acid: a pilot study. Cancer Treat Rep 66: 1803-1807, 1982

31. Ito I, Mukai M, Ninomiya H, Kishima K, Tsuchiya K, Tajima T, Oida Y, Nakamura M and Makuuchi H: Comparison between intravenous and oral postoperative adjuvant immunochemotherapy in patients with stage II colorectal cancer. Oncol Rep 20: 1189-1194, 2008.

32. Mukai M, Sato S, Ninomiya H, Wakui K, Tsuchiya K, Komatsu N, Tajima T, Nakasaki $\mathrm{H}$ and Makuuchi $\mathrm{H}$ : Recurrence and 5-FU sensitivity of stage II/III node-positive gastric cancer with occult neoplastic cells in lymph node sinuses. Oncol Rep 14: 1505-1510, 2005.

33. Mukai M, Sato S, Ninomiya H, Wakui K, Tsuchiya K, Komatsu N, Tajima T, Nakasaki $\mathrm{H}$ and Makuuchi $\mathrm{H}$ : Recurrence and 5-FU sensitivity of stage I/II node-negative breast, lung, or gastric cancer with occult neoplastic cells in lymph node sinuses. Oncol Rep 15: 815-820, 2006

34. Saltz LB, Cox JV, Blanke C, Rosen LS, Fehrenbacher L, Moore MJ, Maroun JA, Ackland SP, Locker PK, Pirotta N, Elfring GL and Miller L: Irinotecan plus fluorouracil and leucovorin for metastatic colorectal cancer. Irinotecan study group. N Engl J Med 343: 905-914, 2000.

35. Tournigand C, Achille TAE, Lledo G, Flesh M, Quinaux DM-ME, Couteau C, Buyse M, Ganem G, Landi B, Colin P, Louvet C and De Gramont A: FOLFIRI followed by FOLFOX 6 or the reverse sequence in advanced colorectal cancer: a randomized GERCOR study. J Clin Oncol 22: 229-237, 2004.

36. Colucci G, Gebbia V, Paoletti G, Giuliani F, Caruso M, Gebbia N, Cartenì G, Agostara B, Pezzella G, Manzione L, Borsellino N, Misino A, Romito S, Durini E, Cordio S, Seri MD, Lopez M and Maiello E: Phase III randomized trial of FOLFIRI versus FOLFOX 4 in the treatment of advanced colorectal cancer: a multicenter study of Gruppo Oncologico Dell'Italia Meridionale. J Clin Oncol 23: 4866-4875, 2005.

37. Mukai M, Sato S, Ninomiya H, Wakui K, Komatsu N, Matsui N, Nakamura M, Nakasaki $\mathrm{H}$ and Makuuchi H: Sensitivity to CPT-11 and platinum derivatives for stage III/Dukes' C colorectal cancer with occult neoplastic cells in lymph node sinuses. Oncol Rep 17: 1027-1032, 2007.

38. Mukai M, Sato S, Ninomiya H, Wakui K, Komatsu N, Matsui N, Nakamura M, Nakasaki $\mathrm{H}$ and Makuuchi $\mathrm{H}$ : Sensitivity to CPT-11 and platinum derivatives for stage II/Dukes' B colorectal cancer with occult neoplastic cells in lymph node sinuses. Oncol Rep 17: 1045-1050, 2007.

39. Feinstein AR, Sosin DM and Wells CK: The Will Rogers phenomenon: stage migration and new techniques as a source of misleading statistics for survival in cancer. N Engl J Med 312: 1604-1608, 1985.

40. Bunt AMG, Hermans J, Smit VTHBM, van de Velde CJH, Fleuren GL and Bruijn JA: Surgical/pathologic stage migration confounds comparisons of gastric cancer survival rates between Japan and Western countries. J Clin Oncol 13: 19-25, 1995. 